\title{
Profits and Speculation in Intra-Day Foreign Exchange Trading
}

\author{
Alexander Mende, University of Hannover, Germany \\ and \\ Lukas Menkhoff, University of Hannover, Germany *
}

Discussion Paper 339

June 2006

ISSN: 0949-9962

\begin{abstract}
This study examines profits and speculation in the USD/EUR trading of a bank in Germany over a four-month period. Dealing activity at the bank generates profits but speculation does not seem to contribute to this. We find that speculative positions fail to become profitable within a 30-minutes' horizon. Also, the suggestion that exchange rate volatility would foster speculative profits cannot be confirmed. To explain daily revenues, neither the bank's speculative trading volume nor its inventory position, but only customer trading emerges as a significant determinant. Furthermore, a spread analysis reveals that there is hardly any room for revenues from speculation.
\end{abstract}

JEL-Classification: $\quad$ G15, F31

Keywords: $\quad$ foreign exchange markets, speculation, profits, market microstructure, flow analysis

We are deeply indebted to the dealers who provided the data and discussed findings with us. We gratefully acknowledge very helpful comments from an anonymous referee and from the responsible editor, Bruce N. Lehmann.

\footnotetext{
* corresponding: Lukas Menkhoff, Department of Economics, University of Hannover, Königsworther Platz 1, D-30167 Hannover, Germany, menkhoff@gif.uni-hannover.de
} 


\section{Profits and Speculation in Intra-Day Foreign Exchange Trading}

\section{Introduction}

Nowadays, microstructure research in foreign exchange markets is seen by many as a promising avenue due to the "failure of the macro approach" (Flood and Taylor, 1996, Madhavan, 2000, and Lyons, 2001). Our deeper understanding of the processes in foreign exchange is hampered, however, by the limited amount of data availability. In particular, profitability is a key source of information to understand the business, but useful profit figures are extremely rare. We contribute to the literature by analyzing a new data set which covers a much longer period than earlier studies. This allows us to apply new methods and to generate more reliable results. We find that our bank does make money in foreign exchange trading, but that speculation does not contribute much to this, if at all. Profits from speculation cannot be identified, either in an event study approach or by regressing potential determinants of profits. Moreover, analyzing spreads in non-speculative trading reveals revenues that fully explain overall profits. Thus, it is not speculation, but providing intermediation services to customers that seems to explain profits best.

The issue of trading profitability is a core element of Friedman's (1953) proposition that profitable speculation would stabilize exchange rate movements. Although the conventional view now seems to be that profits are neither necessary nor sufficient for stabilizing speculation it is nevertheless very interesting to know whether banks' foreign exchange speculation makes profits. Available evidence has not really been satisfying so far. There are several studies analyzing banks' position taking, with lower frequency data, such as monthly data (Fieleke, 1981) or weekly data (Wei and Kim, 1997). We know, however, that banks square their large open positions at the end of the day, hence these kinds of studies miss the bulk of intra-day position taking (see Goodhart, 1988). Unfortunately, evidence from intra-day data is 
even rarer. According to our knowledge, only two studies analyzing profitability in foreign exchange exist, i.e., Lyons (1998) and Yao (1998). Their studies are limited since their data sets are based on one week and five weeks of trading respectively, a disadvantage in identifying a volatile phenomenon (Lyons, 1998). So at this stage, there is still an obvious need for better data which allow for the application of more reliable approaches, and thus, for drawing more general conclusions.

Our data covers the complete tick-by-tick USD/EUR trading record of a bank in Germany over 87 days in 2001. This bank is a "regular" participant in foreign exchange markets as its activities show: first of all, the bank's trading volume in the market segment that we are analyzing is of about average size in comparison to the 33 foreign exchange trading banks in Deutsche Bundesbank's survey of the foreign exchange market in Germany (see details in the Appendix). Second, this bank offers the full range of products, i.e., spot as well as derivatives, it serves commercial as well as financial customers, it participates as a market maker and it conducts own-account trading. All this happens in several currencies. This bank is not as large as the banks covered by Lyons (1998) or Yao (1998) but it is not so tiny that it could be considered marginal, either. Moreover, the bank is not as specialized as Lyons' dealer who trades in the interbank market only. In fact, this bank's customer share of trading volume is $38 \%$, close to the average figure of $41 \%$ for the world-wide foreign exchange market (BIS, 2002, Table B.3). Finally, we identify considerable profits in our bank's foreign exchange trading, whereas Yao does not. Yao's results are somewhat surprising in light of the heavy trading and risk involved and may be due to non-representative circumstances.

Beside the comparison above, there is further information suggesting that the evidence presented here is of potential interest beyond the single case. When analyzing the kind of trading behavior of this bank's USD/EUR dealer, we found that the characteristics are the same as those found in other studies (Osler, Mende and Menkhoff, 2006, have examined this relation 
for other purposes). Moreover, foreign exchange markets seem to be so highly integrated that market-wide characteristics can be reproduced with our case data, such as the correlation between price changes and order flow in the sense of Evans and Lyons (2002). As a last check, we have compared the bank's profits at the four-month period covered here with a three-year period, finding that profits earned at the sample period are about $10 \%$ below average but not misleadingly low.

We do find that our bank earns considerable revenues, i.e., gross profits. When we subtract transaction costs according to a standard approach, we find that this bank also makes (net) profits. We then turn to the core question of whether or not revenues are caused by speculation. Due to the data available we can extend and complement several methods of this literature: we follow Yao's (1998) definition of speculative trades and apply this also to incoming trades. The new application of an event study method shows that speculative positions fail to become systematically profitable over a period of 30 minutes. If we track these positions until they are closed we find profits, but these are partially caused by customer trades. Lyons' (1998) suggestion that exchange rate volatility would foster speculative profits can be tested thanks to the comparatively long data period in a regression approach and his hypothesis is not confirmed by our case. Extending this approach by putting various suggested determinants of profitability into a multivariate regression, only customer business emerges as a significant profit source and not price volatility, nor position taking. Picking up ideas by Lyons (1998) and Yao (1998), we see that a spread analysis of interbank and customer business reveals that there is hardly any room left for residual revenues from speculation. Thus, the tentative finding in the literature that speculation may slightly contribute to foreign exchange trading profits (Lyons, 1998; Yao, 1998) is not confirmed by our examination of this case. Considering the competitive nature of this market, it seems reasonable to doubt that any participant could systematically make money by speculation. 
The paper proceeds as follows: Section 2 introduces the data used. Section 3 presents overall revenues and profits of the dealer's foreign exchange trading. Section 4 discusses approaches to help identify speculative trading activity. Section 5 focuses on identifying possible revenues from speculation. Section 6 concludes.

\section{Data}

The data set employed in this study consists of the complete USD/EUR trading record of a bank in Germany. The record covers 87 consecutive trading days, beginning on Wednesday, 11 July 2001, and ending on Friday, 9 November 2001. Please note that we could not find any enduring change in trading behavior due to a possible "September- $11^{\text {th }}$-effect" (see Mende, 2005). Compared with the other microstructure data sets mentioned (Lyons, 1998, Yao, 1998), this is the longest observation period to date.

Because the bank is an average-sized market-making participant with a limited retail and wholesale customer base, the transaction frequency is comparatively low. The bank realizes about 41 USD/EUR trades per day, including all kinds of transactions, whereas the big market makers covered earlier perform several times as many transactions per day. Referring to the BIS turnover data (see BIS, 2002) it becomes obvious that previous studies on transaction data focus on extremely large dealers. ${ }^{1}$ Our bank is small by contrast but appears to be a reasonable case for a "regular" bank in this market. Here the calculations are performed for the bank and not for a single dealer. However, due to the comparatively small size of our institution, there is only one dealer responsible for the bank's USD/EUR inventory position and trading policy - although he may be supported by other dealers when required - so there is no de facto difference from earlier studies covering single dealers.

\footnotetext{
${ }^{1}$ Yao $(1998$, p.10) says that his dealer is among the top five USD/DEM dealers and Lyons' (1998) dealer trades about the same volume. Top five compares to a total of about 2,500 banks ("reporting dealers") surveyed by the BIS (2002), many of them being active in the leading currency, i.e., USD/DEM with a market share of 20 to 25 per cent during the 1990 s (BIS, 2002, Table B.6).
} 
In order to obtain a broad data set, we include outright-forward trades in an adjusted manner, i.e., by correcting for forward points. In our opinion, these trades should not be disregarded, since we also consider customer trading, and outright-forward trades account for a large portion of customer business. Moreover, outright-forward trades influence the inventory position of our bank, since this trading is also conducted by the same dealer as the spot trading.

The data set consists of all trades, including indirect trades executed by voice-brokers or electronic brokerage systems such as EBS, direct trades completed by telephone or electronically, internal trades and customer trades. For trade size of one million EUR or more in the interbank market, the bank almost solely uses the electronic brokerage system EBS, since communication and transactions require less time there than in any other interdealer trading channel. Moreover, spreads are very advantageous - around one or two pips only, roughly one or two hundredths of one per cent. ${ }^{2}$ All trades are entered manually into the "deals blotter" by the back-office without differentiating between the numerous trading channels of each transaction. The bid-ask quotes at the time of each transaction are not recorded, either, but we can easily identify the bid-ask prices afterwards from the trade-initiating party. For each trade, the following information is obtained from the hardcopy record:

(1) the type of each trade;

(2) the date and time of the trade;

(3) the counterparty;

(4) the quantity traded;

(5) the transaction price;

\footnotetext{
${ }^{2}$ A pip is the smallest unit of an exchange rate quote. For USD/EUR one pip equals USD 0.0001; accordingly, a round trip of say 1 million USD causes spread costs in this brokerage system of about 100 to 200 USD (assuming that twice the half-spread has to be paid). When working with the EBS system our dealer mostly transacts trades of one, two or five million USD/EUR. Interbank trades of more than 5 million USD/EUR are uncommon. In fact there is only one trade above that size in our data.
} 
(6) the forward points if applicable ${ }^{3}$;

(7) the initiator of the trade.

Identifying the initiator of each trade allows for distinguishing between incoming (passive) and outgoing (active) trades. Similar to the finding by Yao (1998, Table 3b), approximately $53 \%$ of all trades are signed as incoming or passive.

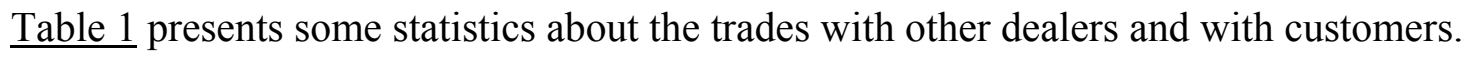
The transaction size of the interdealer trades is very similar to the ones observed by Bjønnes and Rime (2005, Table 2). The share of customer trading volume, amounting to $38 \%$ (21\% spot trades only), is comparatively high as previous studies deal with a customer share of between 0 (Lyons, 1995) and 18\% (Bjønnes and Rime, 2005). ${ }^{4}$ Finally, some cases are deleted from the final data set due to tiny volumes of less than 1,000 USD or the recording of apparent typographical errors (extreme price changes of more than 100 basis points), as both characteristics may blur the correlations of interest.

The final data set is thus composed of all incoming and outgoing spot and outrightforward trades of the interdealer and the customer business.

\section{Overall revenue and profit}

Since the complete trading record is available, it is possible to infer the total revenues.

The only assumption that has to be made - according to Lyons (1995) - is to set the open position at the end of each day to zero. In fact, there are small open positions at the end of the

\footnotetext{
${ }^{3}$ On the basis of the forward points it is possible to transform each outright-forward trade into a "spot-like" trade. This requires that covered interest parity holds, which is a stylized fact for the market under consideration (Sarno and Taylor, 2002, p. 9). We know, however, that due to bid-ask spreads covered interest arbitrage holds only as an approximation and that banks make money from it (see Akram, Rime and Sarno, 2005). Thus, our calculation is not precise but the errors are small because bid-ask spreads are small.

${ }^{4}$ However, we neglected the orders of a third customer group, i.e., so-called "preferred customer" orders. These customers are typically commercial customers with multi-dimensional relationships with the bank, and are omitted here because their spreads may reflect cross-selling arrangements and because their trades are typically very small (average size EUR 0.18 million). Bankers told us that these trades are not intended to be profitable as such. Thus, these orders might distort results here. In fact, when we include "preferred customers" our results do not change structurally, but they become less significant.
} 
day and it is unclear whether they are kept (partially) open until the next day or closed during the night. Nevertheless, these open positions are about EUR 1 million at the median and thus smaller than the median during the day which is above EUR 3 millions. ${ }^{5}$ We calculate trading revenues by multiplying the average daily bid-ask spread with the amount of USD traded each $i^{\text {th }}$ day:

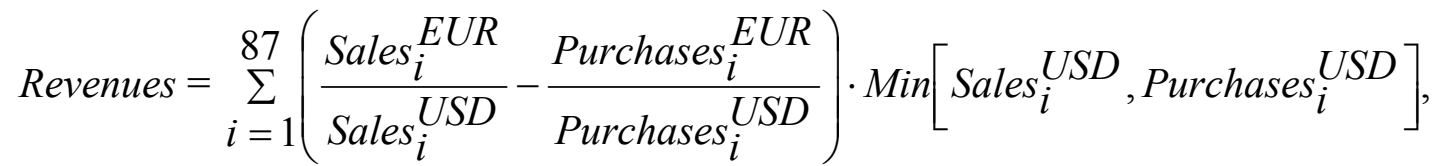

$\operatorname{Sales}_{i}{ }^{U S D}$ (Purchases ${ }_{i}^{U S D}$ ) is the daily amount of USD sold (purchased) and Sales ${ }_{i}^{E U R}$ (Purchases $_{i}^{E U R}$ ) is the corresponding volume in EUR of all USD sales (purchases) of the respective day. This overall bid-ask spread, the first part of eq. (1), is then multiplied with the absolute value of USD traded every day, the second part of eq. (1). If the dealer sold (bought) less USD than he bought (sold) during a trading day, the amount of USD traded is the absolute value of USD sales (purchases). ${ }^{6}$ Thus, with the final open position artificially closed every day without profit or loss, the overall trading revenue during the 87-day period adds up to EUR 966,000. According to conversation with traders, further sources of revenues for the total foreign exchange department come from swap, future and option trades and from trading in other currencies where margins tend to be higher. In addition, senior staff may hold longerterm oriented open positions that can generate profits.

\footnotetext{
${ }^{5}$ To gain potential insight, we have calculated the "overnight profitability" of these open inventory positions. Using market-wide data provided by Olsen Financial Technologies we compare the EUR value of the open USD position at the end of a trading day, 18:00 (MET), with its EUR value at the beginning of the next trading day, 8:00 (MET). These overnight value changes over the whole 87-day sample period actually produce a loss of EUR -287,426. When we change the start of a day to 9:00 (MET) and its end to 17:00 (MET) for our calculation, the bank realizes an overnight loss of EUR $-335,963$. This indicates that possible overnight positions are not a clear and easy source of trading profitability.

${ }^{6}$ For example, on July 20 our bank purchased USD 19,747,403 which corresponded to EUR 22,523,520. On the same day it sold USD 19,506,931 which corresponded to EUR 22,271,747. At the end of the day the bank was long USD 240,472. Thus, with its pure trading activity the bank realized on this day an average bid-ask spread of 11 pips and total trading revenues of EUR 22,505 which is high compared to the bank's average spread of 2.23 pips and average daily revenues of 11,100 EUR (see Table 2). Due to customer business, the bank's average spread is above the interbank spread of 1 to 2 pips.
} 
The "hard" profit figure can be set in relation to the conceptually similar studies of Lyons (1998) and Yao (1998). Table 2 gives comparative information on these studies. Our dealer works for a foreign exchange trading bank where his trading volume per day is 43 million USD per day and thus a fraction of Lyons' 1,400 and Yao's 1,500 million USD per day. This corresponds with trades per day, which is 41 for our dealer, and 344 or 181 respectively for Lyons' and Yao's. However, the revenue figures of this dealer are close to the large competitors: revenue per day is 11 thousand EUR and thus only about $11 \%$ of Lyons' dealer but $66 \%$ of Yao's dealer. When revenue per volume is considered, the gross "margin" of 2.23 basis points, in hundreds of per cent, is markedly higher than the 0.73 and 0.11 basis points for the large dealers. This higher margin is enough to compensate for the smaller trade size, as revenue per trade is 240 USD and thus almost the same as the 295 USD for Lyons' dealer and even ahead of the 94 USD for Yao's dealer.

It is well known from the two earlier studies that trading revenues vary enormously from day to day and that they can even be negative. Yao's dealer, for example, had losses on eight of the 25 trading days covered in the study (Yao, 1998, Table 5). It is therefore no surprise that our dealer also is confronted by quite varying daily results. Figure 1 plots daily revenues with daily trading volume. One can see that there are many days with losses (20 out of 87). Moreover, the revenue is positively related with volume as the coefficient of correlation is 0.52 .

In a last step, it seems worthwhile to calculate not just revenues but also profits. This, at a minimum, requires some information about the administrative costs. Interviews in several trading rooms have shown that foreign exchange trading costs are preferably calculated as costs per trade, largely independent of the trade's size. The costs per trade mentioned by market participants are definitely influenced by several bank-specific factors but the most often mentioned concrete figure for full costs is 100 EUR per trade. Again, it is not fully revealed 
which costs are covered by this figure, whether equity capital costs and risk costs are considered, to what extent overhead costs are included, etc. ${ }^{7}$ However, the figure appears to be useful and it shows that foreign exchange trading at our bank does not only generate revenues but also profits; revenue per trade is 268 EUR on average compared to a cost of 100 EUR which yields a profit of 606 thousand EUR for the four-month period. The cost per trade also indicates that the five weeks trading of Yao's dealer most probably were at the borderline of profitability.

So, revenues and even profits are earned on most days of our dealer's foreign exchange trading. This raises the question whether a speculative position-taking of traders contributes to this result.

\section{Approaches to identify revenues from speculation}

The question whether banks really earn money from their speculative foreign exchange trading has been approached in three ways in the literature: first, position taking is analyzed, in particular position taking in relation to later price changes. Second, it has been suggested that speculation would be more profitable in a volatile environment. Third, due to difficulties in identifying speculative trades, speculative revenues have been regarded as the residual beyond revenues from customer and interbank trades. We will follow these three approaches in Section 5 by analyzing our new data set. What plausible ex ante-expectations about speculative profits can be drawn from empirical exchange rate studies?

The overwhelming finding of the literature is that there exists no economic model to explain exchange rate movements on shorter-term horizons (Frankel and Rose, 1995; Kilian and Taylor, 2003), which seems to make profitable speculation at monthly or weekly horizons

\footnotetext{
${ }^{7}$ The costs considered here apply to the foreign exchange department only. It might well be that the same customers cause costs for the bank at another place that are not fully covered but that have to be accepted in the overall relationship. In this sense the profitable FX business has to be regarded in the context of a possibly less profitable overall customer calculation.
} 
difficult. Fieleke (1981) uses the foreign currency positions of US firms, reported to the US authorities on a monthly basis. The main analysis compares these open positions with later exchange rate changes and does not find a systematic relationship. The work of Wei and Kim (1997) relies on an extended data base which also includes open positions resulting from currency business, available on a weekly basis. This data comprises 36 large players, effectively the leading trading banks. So, if there is respective private information in the foreign exchange market, it might be revealed by analyzing the open positions of these large players over horizons of between one day to 12 weeks. However, the result is quite similar to Fieleke (1981), despite more comprehensive, shorter-term data on the best informed market participants (see also Ammer and Brunner, 1997; Klitgaard and Wei, 2004).

Empirical exchange rate research has found, however, two other starting-points for possibly profitable exchange rate speculation - the very long and the very short end of the market. At the long end, exchange rates show some tendency to behave in accordance with the purchasing power parity (Rogoff, 1996; Taylor and Taylor, 2004). The necessary horizon of years is too long for most foreign exchange professionals but may explain why central banks tend to make money from interventions (Sweeney, 1997).

At the very short end, order flow has been revealed as a measure carrying private information (Ito, Lyons and Melvin, 1998; Covrig and Melvin, 2002; Osler, 2003; Payne, 2003). Moreover, cumulated order flow is related to exchange rate changes (e.g., Evans and Lyons, 2002; Fan and Lyons, 2003). So, if a bank had private information about future order flow, it could profit from this knowledge. In line with this insight into order flow it has been established that banks mostly speculate intra-day.

The first study analyzing such intra-day transaction data is Lyons (1998). He has the trading record data of a very large dealer over one week, generating total revenues of 508 thousand USD. To estimate the speculative profit, Lyons proposes two approaches: first, the 
total bid-ask spread in incoming orders is decomposed, according to the dealer's opinion, into two thirds for laying off the inventory shock and one third remaining revenue from interbank trading (as there is no customer trading). This procedure leads to the necessarily imprecise result that intermediation explains more than $90 \%$ of the total revenue. Thus, speculation - as the residual - explains less than $10 \%$. The second procedure is quite different: here an instrument is suggested to define that share of inventory that is of a speculative nature. This instrument is non-dealt quotes, which contain useful information about past price changes and help the dealer to determine his speculative demand. These non-dealt quotes can explain about one quarter of the dealer's position, which is the speculative part according to this argument. In the next step, Granger causality tests are performed in order to see whether the speculative position forecasts price changes (Lyons, 1998, p. 111). Finally, the value of the speculative position over time is measured. Neither step can identify profitable speculation: speculative positions do not Granger cause price changes, nor is there an indication that speculative positions become more valuable over time, rather the opposite. This identification of speculative position holding may be imprecise, however, since other available information, such as further quotes in the market, volumes, conversations or transactions from voice brokers (that can be known), is not considered.

A critique which Yao (1998) brought forward against this approach is that the decomposition of inventory does not identify the quantity of speculative trading. He thus suggests another measure to identify speculation, i.e., trades that are initiated by the dealer and lead to an increase in inventory, so-called accumulating trades. This definition encompasses $4.2 \%$ of total trading volume of his bank (Yao, 1998, p. 24). However, speculative revenues are calculated as a residual, since he first measures revenue from customer trading and interbank or brokered business and subtracts these revenue sources from the total revenues. In essence, speculative revenue makes up $28.5 \%$ of the total revenue for this bank. However, this ap- 
proach requires the precise identification of trades which close open positions from customer business in order to get spread information. This exact identification is impossible in a strict sense as inventory does not react fully and immediately. So there is room for interpretation of the "true" customer spreads and thus, finally, about the residual of speculative profits.

In summary, even high-frequency data are confronted with the identification problem that inventories simultaneously reflect intermediation of interbank or customer orders and speculative position taking. It is therefore most important to identify speculative trades without interference, for example by accumulating trades that increase inventory (Yao, 1998). Then the profitability of speculative positions should be studied at intra-day horizons. It remains to be seen whether this, as well as other approaches, confirms the finding of Lyons (1998) and Yao (1998), that speculation contributes a small share of overall revenues.

\section{Revenues from speculation}

\subsection{Revenues from accumulating inventory?}

The basic idea in identifying revenues from speculative trading has been to track price changes after position-taking. As discussed above, a conservative but reliable way is to study accumulating (outgoing) interbank trades. The disadvantage of this method is its narrow focus, but one can argue that if the dealer has forecasting ability and if he expands his open positions, then these trades should yield revenues over time. This leaves the possibility open that one is missing other sources of speculation.

We have thus conducted an event study in the sense that whenever the dealer at our bank accumulates inventory via an interbank trade, i.e., at time $t=0$, market price changes before and after this decision are analyzed. ${ }^{8}$ In accordance with Yao (1998) the data are cleaned for cases where the bank obviously increases inventory to serve a later customer order. Re- 
garding the time horizon, one has to consider the short-term orientation of foreign exchange dealers. Half-lives of open positions are in the range of minutes only, in the case of our dealer about 17 minutes (Osler, Mende and Menkhoff, 2006). We decide to consider roughly twice the half-life, a time horizon of 30 minutes before and after engagement in a speculative trade.

Prices available from our main data base are not sufficiently frequent to analyze price changes before and after the accumulating trades and hard to compare due to the different counterparties. Therefore, minute-by-minute quoted midpoint data have been used, which serve as a reasonably close approximation of real prices. These data are taken from the Olson data base which is often used in foreign exchange microstructure studies. ${ }^{9}$ We match both data bases, our bank's data and the Olsen market data, by adjusting the bank's accumulating trades to the market quotes. The absolute exchange rate returns, based on the midpoint quotes (of last bid and last ask quote every minute), are calculated within a time window of 30 minutes before and after $\mathrm{t}=0$. Altogether we identify 322 accumulating interbank trades of speculative nature.

Figure 2 presents results, differentiated by four origins of accumulating inventory. Panels A to D display the following: A shows returns for purchases conducted by outgoing trades only, B shows the same thing for sales. The volume of trades covered by these cases is 6.6 per cent of the total, compared to 4.1 per cent for Yao's (1998) dealer. C and D present returns when purchases and sales were conducted by incoming trades. The latter had not been considered by Yao (1998), as incoming trades are initiated by the counterparty in the setting of direct trades. However, for larger interbank trades our bank relies almost exclusively on the electronic brokerage system, so that the placing of a limit order can be seen as a willingness to

\footnotetext{
${ }^{8}$ Accumulating interbank trades are interdealer spot trades of EUR 1 million and more which lead the bank's inventory away from a zero-position (EUR purchase (sale) increase the long (short) EUR position) and which are not subsequently followed by an unwinding trade.

${ }^{9}$ We first asked for data from the electronic market where our bank mostly trades but were unable to get it. It is known that quotes can differ from real prices and that this difference can be very important for microstructure research (see Evans (2002) in particular the working paper versions). In our case, however, we use the last mid-quote per minute just to get information about the exchange rate movement.
} 
accept open positions at attractive prices. For example, Panel A shows that the USD/EUR exchange rate hardly changes and, thus, stays within the spread for the first 20 minutes. On average, it thereafter decreases after an outgoing EUR purchase. Profits would require a price increase. Whatever approach is taken, the result is always the same: there is no systematic exchange rate movement in the first ten minutes after positions have been taken. During the remaining 20 minutes covered by our analysis, the evidence is sometimes advantageous, especially in Panel C, and less favorable in the three other Panels, particularly in Panel B. To further examine the systematic character of cumulative returns during the 30 minutes window considered, we have compared these returns with bounds of 90 percent cumulative returns of the exchange rate when no speculative positions were taken (grey lines). Realized speculative returns always stay well inside the 90 percent bound, indicating that positions are not systematically good or bad. Overall, there is no indication that this dealer would systematically be able to accumulate inventory in advance of later favorable price changes.

In order to get more complete information about the possible success of accumulating trades, we also follow each trade until the open position has been closed again. Table 3 summarizes information for the four Panels distinguished in Figure 2. Indeed, the cases covered by Panel $\mathrm{C}$ which seemed to be most favorable regarding returns during the first 30 minutes are the most profitable, whereas the cases covered by Panel B generate losses. Overall, accumulating trades, i.e., speculation, seems to be profitable from this viewpoint. The problem is, however, that those trades that close the earlier open positions will often include customer trades. The total profit calculated thus consists of two components which we cannot disentangle: possible speculative revenues and revenues from customer spreads. We conclude that revenues from speculation are marginal at best. 


\subsection{Revenues due to price volatility?}

Another strong statement helpful for identifying speculative revenues is from Lyons (1998, p. 106): "Of course, if profits derive primarily from speculative positions, then volatility is more important than volume." Therefore it seems relevant for us to analyze, first, the relations between volatility and speculation, second, the relation between volatility and revenues and third, the relative importance of volatility versus trading volume.

Price volatility during the day is a prerequisite for earning money from position taking. However, revenues are so small compared to the volumes that tiny price changes would already be theoretically large enough to make considerable surplus. Despite this theoretical possibility, it seems plausible that larger volatility provides even better opportunities for able speculators. To test this hypothesis for our dealer, we look at the volatility around the occurrence of accumulating interbank trades. If these transactions really are of speculative nature then volatility around these trades should be higher than otherwise. We have summed up squared exchange rate returns 30 minutes before and after our 322 "speculative deals" which were identified in the previous section. A t-test strongly rejects the Null that volatility 30 minutes before and after a speculative trade is the same as on average (t-value 8.99). Thus, we find indeed that the dealer speculates more during times of high volatility. This activity does not necessarily generate revenues, however.

Hence, as a next step, a simple rank correlation is run between daily revenues and daily realized exchange rate volatility. ${ }^{10}$ Realized volatility is thereby calculated for the market from the minute-by-minute midpoint quotes which are again taken from the Olsen data base (see Section 5.1). In Table 4, however, Panel A shows that volatility does not seem to be significantly related to revenues.

\footnotetext{
${ }^{10}$ We decided to use the realized volatility, i.e., sum of squared changes between the logs of the exchange rate. Several papers have documented the excellent performance of realized volatility as a volatility measure and it is in common use, especially in high-frequency data analyses (see, for example, Poon, Blair and Taylor, 2001, or Andersen, Bollerslev and Meddahi, 2003).
} 
In a third approach, we directly test Lyons' comparative statement, claiming that volatility may lead to position taking, whereas volume may represent various kinds of business, such as handling incoming (customer) orders. The inclusion of trading volume can also be understood as a control variable, as the influence from volatility on revenues might be compensated by negatively related revenues from other sources, such as customer trading. The result from the baseline regression in Table 4, Panel B is very clear on the relative importance of these competing sources of revenues: it is only volume that is significantly influential and this result holds for modifications of the baseline regression as well, such as splitting the sample, using different volatility measures or applying several kinds of volumes (not reported here).

In summary, our comparatively long time period of 87 days allows us to test for a systematic influence of daily volatility on daily revenues. No relation can be found, indicating in the sense of Lyons (1998) - that position taking would generate revenues for our bank via exploiting price volatility.

\subsection{Systematic correlations of daily revenues}

This section extends the approach chosen above, to explain daily revenues more systematically. In a first step, relevant variables are correlated with each other (see Table 5). The matrix reveals many high coefficients, which can make multivariate analyses problematic. In particular, inventory and inter-transaction time are related to aggregated and disaggregated trading volumes, which arise naturally from the fact that any trade causes an inventory, even though possibly for an extremely short time. Also, higher daily trading volumes imply more transactions per day as order sizes often are standardized, especially in the interbank market. Thus, higher trading volumes tend to generate shorter inter-transaction times. Therefore, it would be misleading to simply take the inventory position (or the time-weighted inventory position) as a proxy for speculative activity. We have to adjust both, inventory and inter- 
transaction time for the influence of trading volume, before we can make use of this variable in our regression analysis, trying to explain daily trading revenues. ${ }^{11}$ In addition, we also rely on those activities that are almost definitely of speculative nature, the accumulating trades.

The strong positive correlation between accumulating interbank trades and realized exchange rate volatility indicates that we have possibly correctly identified trades of speculative nature in Section 5.1.

Putting the variables from Table 5 into univariate regressions to explain revenue for 87 trading days shows that volumes have clear explanatory power, but that the other variables, such as price trend, volatility and adjusted time-weighted inventory position do not (not reported here). Testing several multivariate regressions always leads to a similar finding: volumes are significant, but indicators for speculative activity are not (see Table 6). Disaggregating volume according to the two main counterparty-groups shows that customers are the most significant factor when explaining daily revenues, whereas a positive revenue effect from interbank trading (speculative or not) is questionable. Whereas proxies for intermediating interbank activities have a positive, but insignificant, influence on daily trading revenues, the coefficient on accumulating interbank trades even has a negative sign. Neither volatility nor position taking significantly fosters revenues.

These results point clearly and consistently towards a negligible role of speculation and a more important role of customer business for the foreign exchange trading revenues of our bank.

\footnotetext{
${ }^{11}$ We multiply the residuals of a univariate regression of trading volume explaining the absolute value of the average inventory position with the residuals of another univariate regression of trading volume explaining the average inter-transaction time. The resulting variable is the volume-adjusted and time-weighted open inventory position during each trading day - a proxy for the extent of speculative trading activity at our bank.
} 


\subsection{Revenues beyond non-speculative trading?}

The third approach from the literature for learning about speculative revenues (see Section 4) is to estimate non-speculative revenue components, which may be calculated more easily than the speculative ones. The speculative revenues are the residuals after subtracting those other revenues from total trading revenues. Lyons' (1998) suggestion to generally decompose the bid-ask spread cannot be justified here due to the high heterogeneity of trades. Unfortunately, Yao's (1998) approach of calculating packages of customer plus compensating interbank trades cannot be followed either. Our bank has a much bigger share of customer trades which partially compensate each other. Moreover, this bank does not adjust inventory shocks as fully and as quickly as Yao's bank does, possibly because the absolute size of open positions is often quite small. So, choosing packages in Yao's sense would be highly arbitrary.

Fortunately, there may be another approach to roughly estimate revenues from nonspeculative trades. For this purpose we rely on the workhorse model in foreign exchange microstructure work, the Lyons (1995) variant of Madhavan and Smidt (1991). According to this model pricing decisions on incoming orders will be influenced, among other things, by three interesting effects: first, an asset's own inventory (I) will influence price setting towards a mean-reversion of the inventory, in short the inventory effect. Second, dealers acknowledge asymmetric information among market participants in the sense that they assume private information when they set prices for a larger potential deal. They protect themselves against this assumed information disadvantage by setting larger spreads for larger orders (order size Q); in short, the information effect. Finally, traders live from buying low and selling high, so that a spread (D) is to be expected. The model provides a simple linear expression for the price change between incoming transactions:

$$
\Delta p_{t}=\alpha+\beta Q_{t}+\gamma_{1} I_{t}+\gamma_{2} I_{t-1}+\delta_{1} D_{t}+\delta_{2} D_{t-1}+\eta_{t}
$$


Here, $\Delta \mathrm{p}_{\mathrm{t}}$ captures the price change between two transactions; $\mathrm{Q}_{\mathrm{t}}$ represents the value of the order; $\mathrm{I}_{\mathrm{t}}$ and $\mathrm{I}_{\mathrm{t}-1}$ represent the dealer's current and lagged inventory; the dummy-variables $\mathrm{D}_{\mathrm{t}}$ and $\mathrm{D}_{\mathrm{t}-1}$ represent the current and lagged direction of trade - positive (negative) when the counterparty buys (sells) the commodity currency (EUR, for our dealer); $\eta_{\mathrm{t}}$ represents a random error. We measure price changes in pips; we measure deal and inventory sizes in EUR millions.

We slightly extend the above mentioned baseline model to consider the two origins of incoming trades here, interbank and customer orders. The result is shown in Table 7, Panel A. This approach gives so-called baseline spreads for each group, the lagged direction variables. For customer trades, the average baseline spread is thus roughly nine basis points, for interbank trades it is below two basis points. Taking these spreads and multiplying them by respective volumes leads to the result shown in Panel B of Table 7 in more detail. The spreadgenerated revenues for customers already lead to total revenues of 1,440 thousand EUR (see Panel B) and thus more than the true total revenues of 966 thousand EUR (see Section 3). This indicates that customer business alone is able to fully explain observed profits in intraday trading.

\section{Conclusions}

This analysis of a bank's trading record has revealed new findings about profits and speculation in foreign exchange trading. First of all, we find that our bank does indeed generate considerable revenues as well as profits from its foreign exchange trading operations. It is difficult to assess from the outside how satisfying the profitability for the overall bank is regarded, but considerable profits are real. The degree of profitability is between the two other cases of large banks documented before us (Lyons, 1998, Yao, 1998). Second, speculative position taking is practiced by the bank but cannot be identified as profitable. This is some- 
what surprising, as earlier studies indicated some, although not large, revenues from speculative trading.

In detecting revenues from intra-day foreign exchanges speculation we have applied new approaches, making use of the detailed and long sample at hand. An event study approach has been used to track prices when the bank had become engaged in accumulating trades: there is no indication that revenues are earned. In another approach, profits have been related to volatility in the foreign exchange market. We recognize that the bank does speculate more heavily in volatile markets, but it does not seem to be able to take advantage of volatile markets. Extending this regression, several potential profit sources have been put into a multivariate approach, which shows that neither speculation nor interbank trading contribute much to revenues, in fact it is only customer business that is significantly related to profits. Seen from the opposite side, i.e., from spreads identified in customer business, the latter can explain all revenues earned and leaves no room for speculative profits.

The common ground for these findings is the competitive environment of one of the largest financial markets in the world, the USD/EUR-market. Fundamental information in this market is generally available to all professional market participants at the same time. It is well known that foreign exchange markets react in a systematic manner to this information (Andersen, Bollerslev, Diebold and Vega, 2003) but it is difficult to imagine that a bank would have a systematic advantage in interpreting this information. So, speculation may be based on other kinds of information, such as anticipating central bank intervention (Peiers, 1997), exploiting technical analysis or incoming order flow (as in other financial markets) (see Schultz, 2003). Again, it will be difficult to gain a systematic advantage from these sources, as techni- 
cal analysis tools are available to competitors, too, and as order flow basically is contemporaneous in relation to exchange rates. ${ }^{12}$

Obviously, our bank serves its customers competitively, and they do not care too much about a spread of 5 or 10 basis points. However, this small spread is enough for our bank to unload positions, to manage its overall inventory and to cover administrative costs. This successful service makes clear, moreover, that this bank - and possibly other banks as well - is not engaged in stabilizing speculation in Friedman's sense.

\footnotetext{
${ }^{12}$ Recently, Evans and Lyons (2004) state some forecasting power of flows on later realization of fundamentals but this finding is based on a broad sample of flows, covering about ten per cent of the market, whereas most participants, such as our bank, regard flows to a degree that is not representative for the market.
} 


\section{References}

Akram, F., D. Rime and L. Sarno. 2005. Arbitrage in the foreign exchange market: turning on the microscope. Working Paper, Norges Bank.

Ammer, J. and A.D. Brunner. 1997. Are banks market timers or market makers? Explaining foreign exchange trading profits. Journal of International Financial Markets, Institutions and Money 7, 43-60.

Andersen, T.G., T. Bollerslev, F.X. Diebold and C. Vega. 2003. Micro effects of macro announcements: real-time price discovery in foreign exchange. American Economic Review 93, 38-62.

Andersen, T.G., T.Bollerslev and N. Meddahi. 2003. Correcting the errors: volatility forecast evaluation using high-frequency data and realized volatilities. Working Paper.

Bank for International Settlements [BIS]. 2002. Triennial central bank survey, foreign exchange and derivatives market activity in 2001. Basel.

Bjønnes, G.H. and D. Rime. 2005. Dealer behavior and trading systems in foreign exchange markets. Journal of Financial Economics 75, 571-606.

Covrig, V. and M. Melvin. 2002. Asymmetric information and price discovery in the FX market: does Tokyo know more about the Yen?. Journal of Empirical Finance 9, 271-285.

Evans, M.D.D. 2002. FX trading and exchange rate dynamics. Journal of Finance 57, 24052446.

Evans, M.D.D. and R.K. Lyons. 2002. Order flow and exchange rate dynamics. Journal of Political Economy 110, 170-180.

Evans, M.D.D. and R.K. Lyons. 2004. Do markets learn about fundamentals from order flow? Working Paper, UC Berkeley.

Fan, M. and R.K. Lyons. 2003. Customer trades and extreme events in foreign exchange, in: P. Mizen (ed.), Monetary history, exchange rates and financial markets: essays in honour of Charles Goodhart, Edward Elgar: Northampton, 160-179.

Fieleke, N.S. 1981. Foreign-currency positioning by U.S. firms: some new evidence. Review of Economics and Statistics 63, 35-42.

Flood, R.P. and M.P. Taylor. 1996. Exchange rate economics: what's wrong with the conventional macro approach?, in: J.A. Frankel, G. Galli and A. Giovannini (eds.), The microstructure of foreign exchange markets. University of Chicago Press: Chicago and London, 261-294.

Frankel, J.A. and A.Rose. 1995. Empirical research on nominal exchange rates, in: G. Grossmann and K. Rogoff (eds.), Handbook of International Economics, Vol.III, North-Holland: Amsterdam et al., 1689-1729.

Friedman, M. 1953. The case for flexible exchange rates, in: Essays in positive economics. University of Chicago Press: Chicago, 157-203.

Gehrig, T. and L. Menkhoff. 2004. The use of flow analysis in foreign exchange: exploratory evidence. Journal of International Money and Finance 23, 573-594.

Goodhart, C. 1988. The foreign exchange market: a random walk with a dragging anchor. Economica 55, 437-460. 
Ito, T., R.K. Lyons and M. Melvin. 1998. Is there private information in the FX market? The Tokyo experiment. Journal of Finance 53, 1111-1130.

Kilian, L. and M.P. Taylor. 2003. Why is it so difficult to beat the random walk forecast of exchange rates? Journal of International Economics 60, 85-107.

Klitgaard, T. and L. Weir. 2004. Exchange rate changes and net positions of speculators in the futures market. Federal Reserve Bank of New York Economic Policy Review 10, 17 28.

Lyons, R.K. 1995. Tests of microstructural hypotheses in the foreign exchange market. Journal of Financial Economics 39, 321-351.

Lyons, R.K. 1998. Profits and position control: a week of FX trading. Journal of International Money and Finance 17, 97-115.

Lyons, R.K. 2001. The microstructure approach to exchange rates. MIT Press: Cambridge.

Madhavan, A. 2000. Market microstructure: a survey. Journal of Financial Markets 3, $205-$ 258.

Madhavan, A. and S. Smidt. 1991. A Bayesian model of intraday specialist pricing. Journal of Financial Economics 30, 99-134.

Mende, A. 2005. 09/11 on the USD/EUR Foreign Exchange Market. Applied Financial Economics, forthcoming.

Osler, C. 2003. Currency orders and exchange-rate dynamics: an explanation for the predictive success of technical analysis. Journal of Finance 58, 1791-1820.

Osler, C., A. Mende and L. Menkhoff. 2006. Price discovery in currency markets. Working Paper, Brandeis University.

Payne, R. 2003. Informed trade in spot foreign exchange markets: an empirical investigation. Journal of International Economics 61, 307-329.

Peiers, B. 1997. Informed traders, intervention and price leadership: a deeper view of the microstructure of the foreign exchange market. Journal of Finance 52, 1589-1614.

Poon, S.-H., B. Blair and S. Taylor. 2001. Forecasting S\&P 100 volatility: Using high frequency data and implied volatility, Journal of Econometrics 105, 5-26.

Rogoff, K. 1996. The purchasing power parity puzzle. Journal of Economic Literature 34, 647-668.

Sarno, L. and M.P. Taylor. 2002. The economics of exchange rates. Cambridge University Press: Cambridge et al.

Schultz, P. 2003. Who makes markets. Journal of Financial Markets 6, 49-72.

Sweeney, R.J. 1997. Do central banks lose on foreign-exchange intervention? A review article. Journal of Banking and Finance 21, 1667-1684.

Taylor, A.M. and M.P. Taylor. 2004. The purchasing power parity debate. Journal of Economic Perspectives 18, 135-158.

Wei, S.-J. and J. Kim. 1997. The big players in the foreign exchange market: do they trade on information or noise? Review of International Economics, forthcoming [NBER Working Paper 6256].

Yao, J.M. 1998. Spread components and dealer profits in the interbank foreign exchange market. Working Paper S-98-4, Stern School of Business, New York University. 


\section{Table 1 Types of trades}

The table shows the USD/EUR trading activity of a small bank in Germany over the 87 trading days between July $11^{\text {th }}, 2001$, and November $9^{\text {th }}, 2001$. Preferred commercial customer trades are excluded.

\begin{tabular}{llll}
\hline & All trades & $\begin{array}{l}\text { All trades } \\
\text { Interbank }\end{array}$ & Customer \\
\hline $\begin{array}{l}\text { Number of trades } \\
\text { (per cent) }\end{array}$ & 3,609 & 1,919 & 1,690 \\
Value of trades (EUR millions) & 100 & 44 & 56 \\
(per cent) & 4,335 & 2,726 & 1,609 \\
Mean size (EUR millions) & 100 & 62 & 38 \\
Median size (EUR millions) & 1.20 & 1.42 & 0.95 \\
\hline
\end{tabular}

Table 2 Revenue data of three banks

\begin{tabular}{|c|c|c|c|c|}
\hline & \multicolumn{2}{|c|}{ This paper } & \multirow{2}{*}{$\begin{array}{l}\text { Lyons (1998) } \\
\text { in USD }\end{array}$} & \multirow{2}{*}{$\begin{array}{l}\text { Yao }(1998) \\
\text { in USD }\end{array}$} \\
\hline & in EUR & in USD & & \\
\hline Revenue (thousands) & 966 & 867 & 508 & 424 \\
\hline Days considered & 87 & 87 & 5 & 25 \\
\hline Revenue per day (thousands) & 11.1 & 10.0 & 101.6 & 17.0 \\
\hline Trading volume (millions) & 4,335 & 3,699 & 6,969 & 38,217 \\
\hline $\begin{array}{l}\text { Share of customer trading volume (per } \\
\text { cent) }\end{array}$ & 38 & & 0 & 14 \\
\hline Trading volume per day (millions) & 50 & 43 & 1,394 & 1,529 \\
\hline Revenue per volume (basis points) & 2.23 & 2.34 & 0.73 & 0.11 \\
\hline Number of trades & 3,609 & 3,609 & 1,720 & 4,518 \\
\hline Number of trades per day & 41 & 41 & 344 & 181 \\
\hline Revenue per trade & 268 & 240 & 295 & 94 \\
\hline \multicolumn{5}{|l|}{ Revenue per day (thousands) } \\
\hline Minimum & -18 & -17 & 40 & -140 \\
\hline Maximum & 70 & 63 & 200 & 150 \\
\hline
\end{tabular}


Figure 1 Daily trading volume and daily revenues

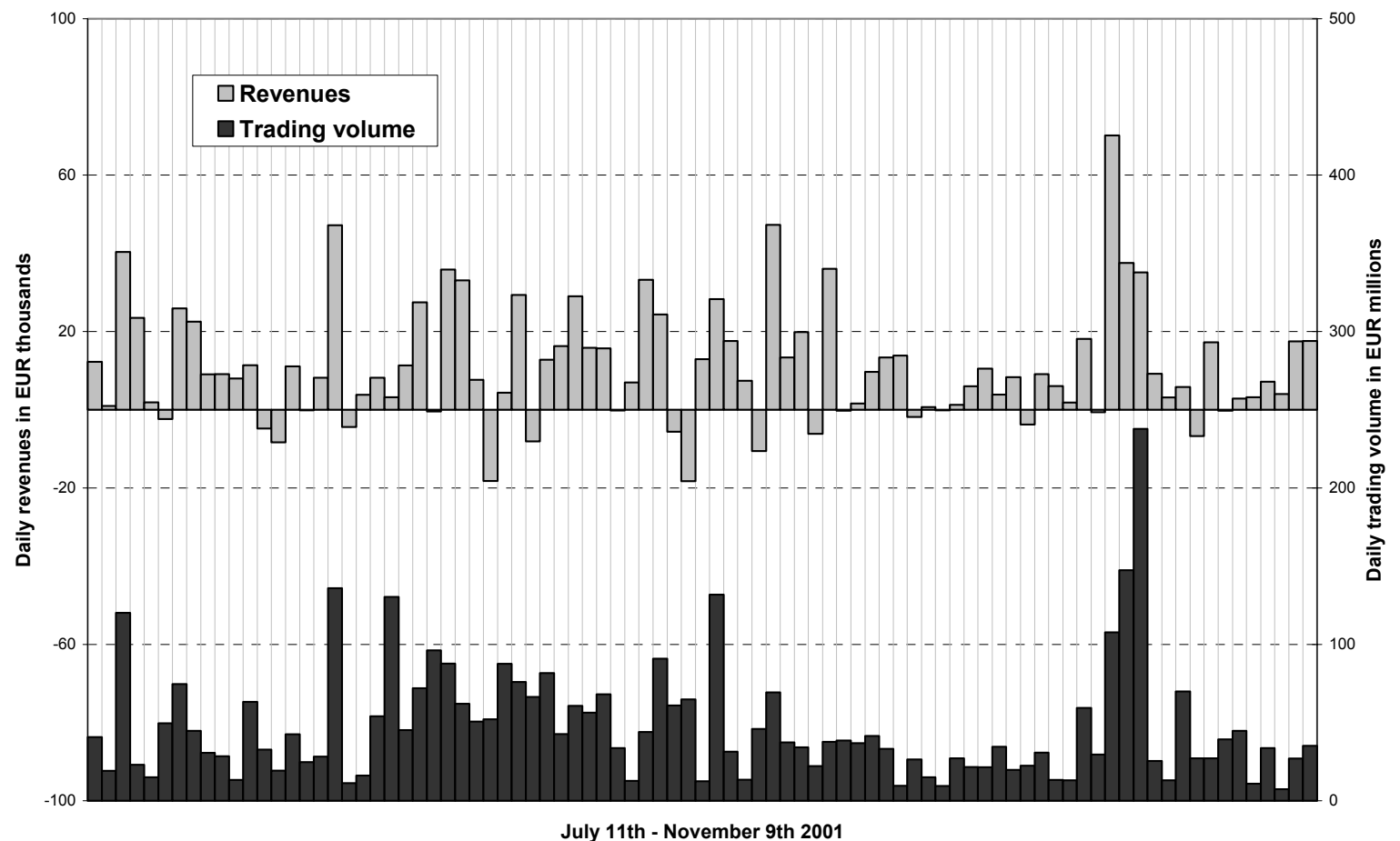

Figure shows daily overall trading revenues measured in EUR thousands and daily trading volume measured in EUR millions for all trades - interbank, financial and commercial customer trades, over the whole sample period $(07 / 11 / 01-11 / 09 / 01)$. 
Figure 2 Exchange rate returns for accumulating interbank trades within a $90 \%$ confidence interval

A

Outgoing interbank trades: EUR purchases and exchange rate returns (42 trades, trading volume: EUR 69 million)

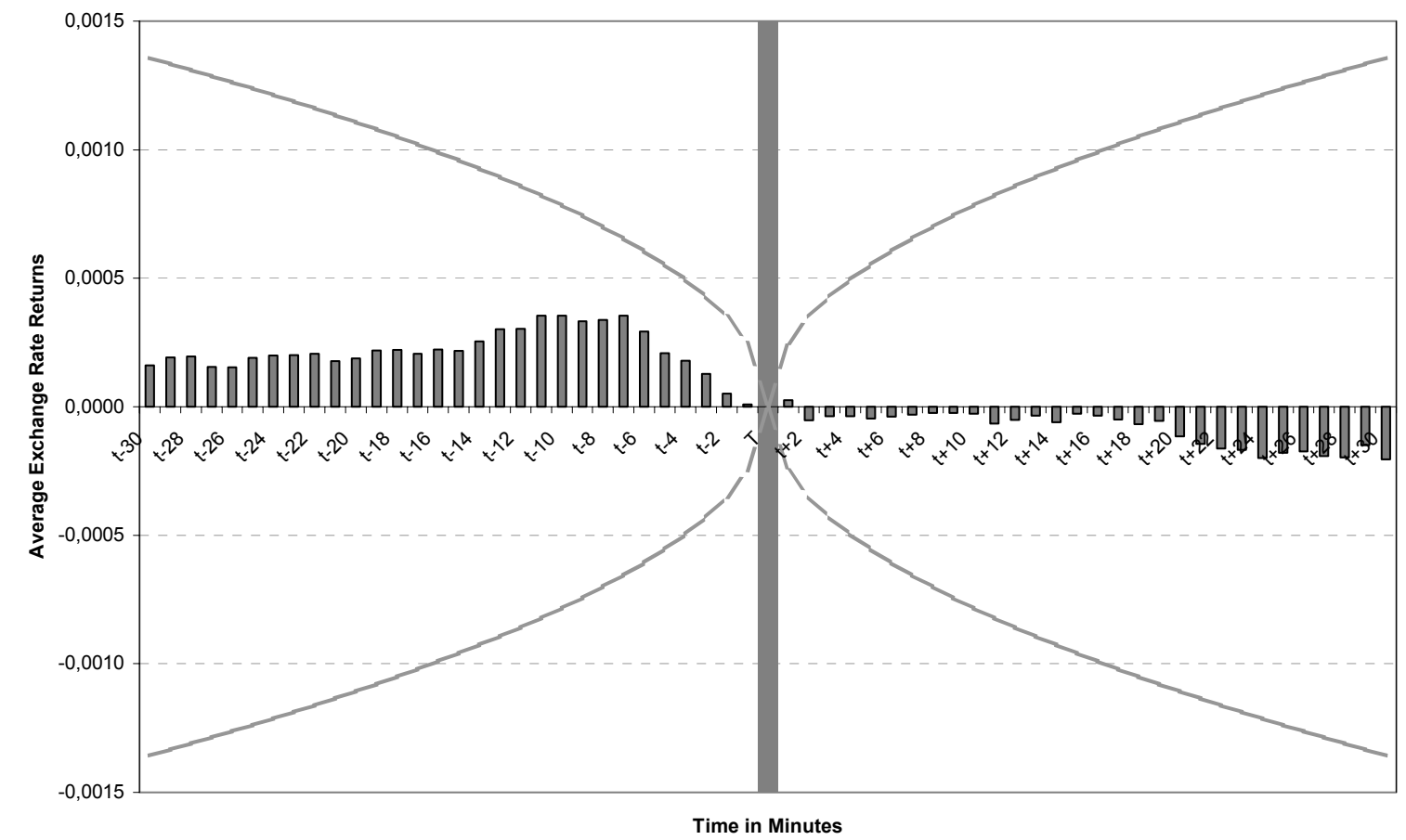

B Outgoing interbank trades: EUR sales and exchange rate returns (103 trades, trading volume: EUR 201 million)

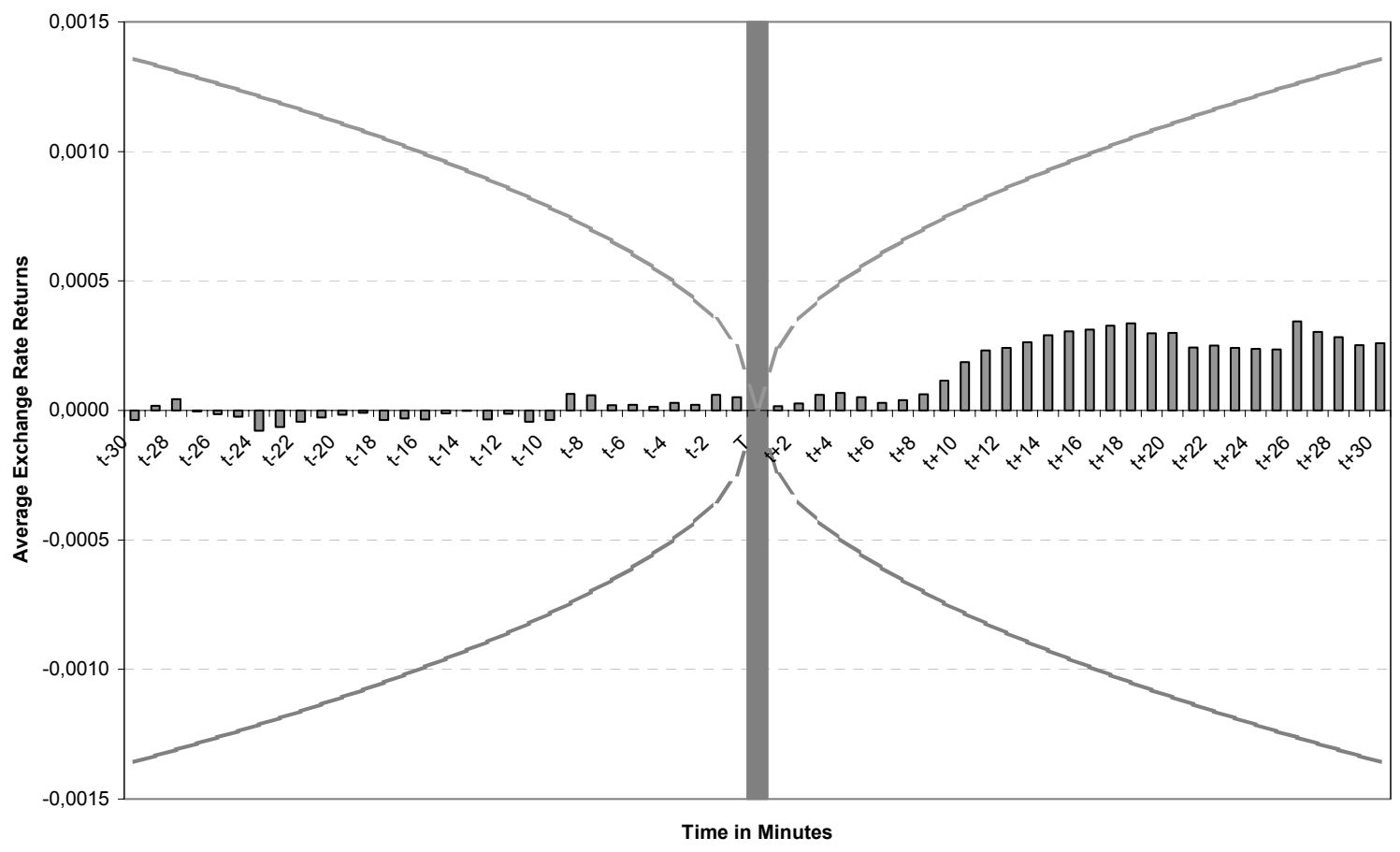

Plot shows the developments of exchange rate returns 30 minutes before and 30 minutes after accumulating outgoing interbank trades (hitting a limit order), i.e. for EUR purchases and EUR sales respectively. Accumulating interbank trades are spot interdealer FX trades of EUR 1 million and more, which lead the bank's inventory away from a zero-position and which are not directly followed by an unwinding trade. The grey lines form a $90 \%$ confidence interval which is based on the assumption that the exchange rate follows a random walk and has a symmetric distribution. 


\section{Figure 2 Exchange rate returns for accumulating interbank trades within a $90 \%$ confidence interval (continued)}

C Incoming interbank trades: EUR purchases and exchange rate returns (58 trades, trading volume: EUR 94 million)

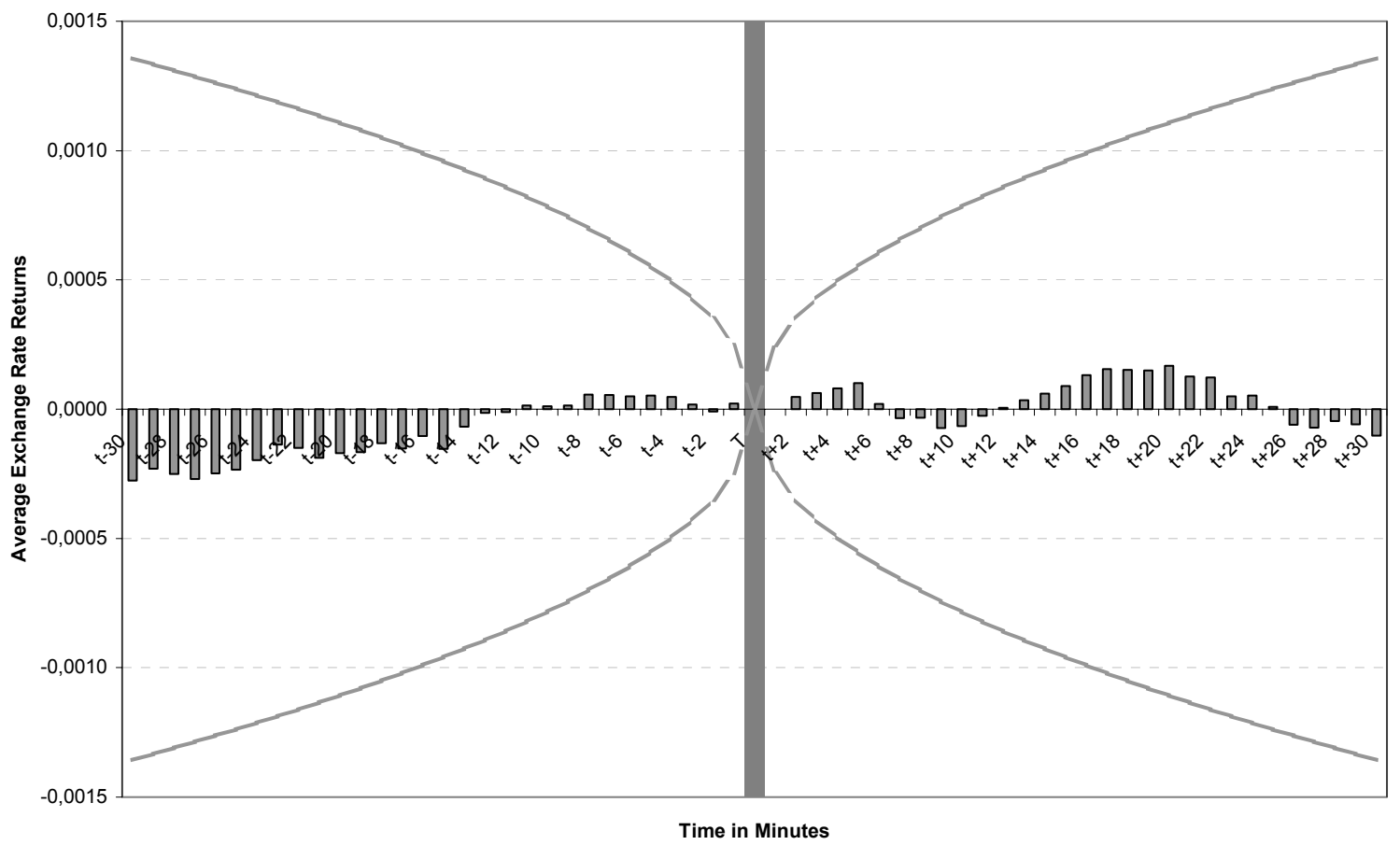

D Incoming interbank trades: EUR sales and exchange rate returns (119 trades, trading volume: EUR 178 million)

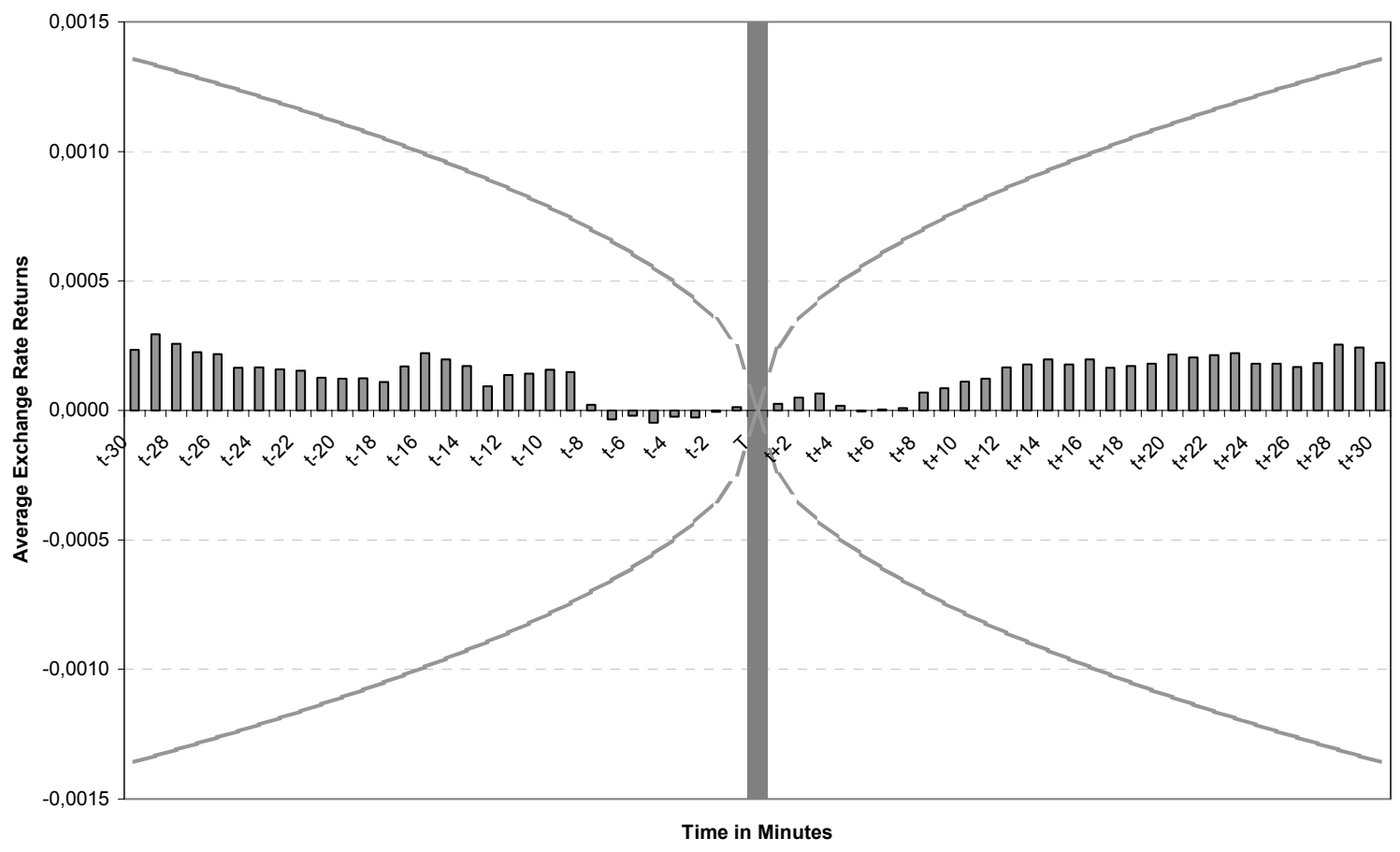

Plot shows the developments of exchange rate returns 30 minutes before and 30 minutes after accumulating incoming interbank trades (limit orders), i.e. for EUR purchases and EUR sales respectively. Accumulating interbank trades are spot interdealer FX trades of EUR 1 million and more, which lead the bank's inventory away from a zero-position and which are not directly followed by an unwinding. The grey lines form a $90 \%$ confidence interval which is based on the assumption that the exchange rate follows a random walk and has a symmetric distribution. 


\section{Table 3 Revenues by reversing accumulating interbank trades}

Table shows the potential revenues gained through reversing accumulating interbank trades shown in Figure 2, Panels A - D. Reversing trades can either be following interbank or customer trades with opposite sign. Calculation uses a strict first-in-first-out procedure (FIFO). A partial amount of the last subsequent trade is used to fully square the accumulated open position. Revenues by reversing accumulating interbank trades sum up to EUR 55,625 which is roughly $6 \%$ of the overall trading revenues of EUR 966 thousand.

\begin{tabular}{|l|rrrr|r|}
\hline & $\begin{array}{c}\text { EUR purchases } \\
\text { Outgoing tra- } \\
\text { des }\end{array}$ & $\begin{array}{c}\text { EUR sales } \\
\text { Outgoing } \\
\text { trades }\end{array}$ & $\begin{array}{c}\text { EUR purchases } \\
\text { Incoming tra- } \\
\text { des }\end{array}$ & $\begin{array}{c}\text { EUR sales } \\
\text { Incoming } \\
\text { trades }\end{array}$ & \\
\hline No. trades & 42 & 103 & 58 & 119 & 322 \\
Volume (EUR millions) & 69 & 201 & 94 & 178 & 542 \\
\hline Sum & 9,866 & $-25,843$ & 44,618 & 26,984 & 55,625 \\
Mean & 274 & -94 & 1,115 & 380 & 173 \\
Median & 465 & 0 & -358 & 608 & \\
Max & 18,353 & 25,792 & 49,375 & 25,257 & \\
Min & $-9,737$ & $-21,677$ & $-8,498$ & $-15,972$ & \\
Std.Dev. & 4,497 & 3,528 & 9,372 & 5,255 & \\
\hline Av. spread (pips by volume) & 1.4 & -1.3 & 4.7 & 1.5 & 1.0 \\
\hline
\end{tabular}

\section{Table 4 Relations between daily revenues, exchange rate volatility and trading vol- ume}

Dependent variable is daily trading revenues measured in EUR thousands. Realized exchange rate volatility is calculated by summing up squared exchange rate returns minute by minute for each day using the Olsen data base. Trading volume is the overall daily trading volume of the bank measured in EUR millions. Estimation uses ordinary least squares with a Newey-West HAC standard errors and covariance controlling for heteroscedasticity. Standard errors and t-values are reported in the $3^{\text {rd }}$ and $4^{\text {th }}$ column, and "***" and "**" indicate significance at the $1 \%$ and $5 \%$-level respectively.

\section{Panel A Revenues and exchange rate (ER) volatility}

Dependent Variable: Trading revenues in EUR thousands

Variable Coefficient Std. Error t-Statistic

Constant $* * 6.738$

3.11

Realized exchange rate volatility 13.506 8.23 1.64

Adjusted $\mathrm{R}^{2}$ 0.02

Durbin-Watson stat 1.89

Number of observations

87

\section{Panel B Revenues, volatility and trading volume}

Dependent Variable: Trading revenues in EUR thousands

Variable

Coefficient

Std. Error t-Statistic

Constant

0.149

2.39

0.06

Realized exchange rate volatility

3.909

7.79

0.50

Trading volume in EUR millions

Adjusted $\mathrm{R}^{2}$ $* * * 0.205$

0.04

4.87

Durbin-Watson stat

0.26

Number of observations 
Table 5 Correlations between daily revenues and relevant variables

\begin{tabular}{|c|c|c|c|c|c|c|c|c|c|}
\hline & $\begin{array}{l}\text { Trading } \\
\text { revenues }\end{array}$ & $\begin{array}{l}\text { Tradir } \\
\text { Total }\end{array}$ & $\begin{array}{l}\text { ng volumes } \\
\text { Accumulating in- } \\
\text { terbank trades }\end{array}$ & $\begin{array}{l}\text { Incoming in- } \\
\text { terbank trades }\end{array}$ & $\begin{array}{l}\text { Outgoing in- } \\
\text { terbank trades }\end{array}$ & $\begin{array}{l}\text { Cus- } \\
\text { tomer } \\
\text { trades }\end{array}$ & $\begin{array}{l}\text { Realized ex- } \\
\text { change rate } \\
\text { volatility }\end{array}$ & $\begin{array}{l}\text { Average absolute } \\
\text { inventory position }\end{array}$ & $\begin{array}{l}\text { Average inter- } \\
\text { transaction time }\end{array}$ \\
\hline Trading revenues & 1.00 & & & & & & & & \\
\hline \multirow{5}{*}{ 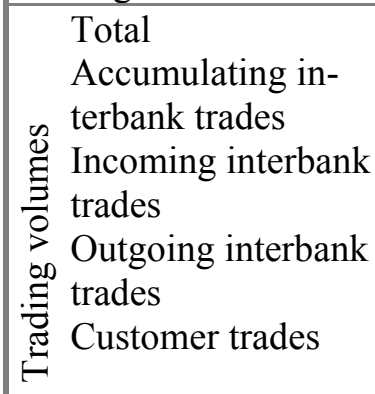 } & 0.52 & 1.00 & & & & & & & \\
\hline & 0.24 & 0.51 & 1.00 & & & & & & \\
\hline & 0.37 & 0.61 & 0.47 & 1.00 & & & & & \\
\hline & 0.43 & 0.69 & 0.26 & 0.47 & 1.00 & & & & \\
\hline & 0.45 & 0.91 & 0.23 & 0.32 & 0.51 & 1.00 & & & \\
\hline \multirow{3}{*}{$\begin{array}{l}\text { Realized exchange rate } \\
\text { volatility } \\
\text { Average absolute in- } \\
\text { ventory position } \\
\text { Average inter- } \\
\text { transaction time }\end{array}$} & 0.18 & 0.25 & 0.66 & 0.28 & 0.13 & 0.04 & 1.00 & & \\
\hline & 0.52 & 0.49 & 0.48 & 0.40 & 0.40 & 0.63 & 0.36 & 1.00 & \\
\hline & -0.30 & -0.51 & -0.46 & -0.62 & -0.47 & -0.30 & -0.28 & -0.42 & 1.00 \\
\hline
\end{tabular}

Realized exchange rate volatility is the sum of minute-by-minute squared exchange rate returns taken from the Olsen data set. Average absolute inventory position is the absolute value of the average open EUR inventory position of the bank during its trading day measured in millions. Average inter-transaction time is the average time between two successive transactions measured in minutes. 


\section{Table 6 Determinants of daily trading revenues}

The dependent variable is daily trading revenues measured in EUR thousands. Daily interbank trading volume is split up into accumulating, incoming and outgoing trading volumes measured in EUR millions. Daily customer trading volume is divided into commercial customers and financial customers, with trading volume measured in EUR millions. The realized exchange rate volatility is calculated by summing up squared exchange rate returns every minute for a whole day using the Olsen data set. The variable "adjusted time-weighted open inventory position" is generated by multiplying the residuals of "trading volume in EUR millions explaining the absolute value of average open inventory position in EUR millions" with the residuals of "trading volume in EUR millions explaining average inter-transaction time". Estimation uses ordinary least squares with a Newey-West HAC standard errors and covariance controlling for heteroscedasticity. Standard errors and t-values are reported in the $3^{\text {rd }}$ and $4^{\text {th }}$ column, and "***" and "**" indicate significance at the $1 \%$ and $5 \%$-level respectively.

Dependent Variable: Daily trading revenues in EUR thousands

\begin{tabular}{lrrr}
\hline Variable & Coefficient & Std. Error & t-Statistic \\
\hline $\begin{array}{l}\text { Constant } \\
\begin{array}{l}\text { Accumulating interbank trading volume in EUR } \\
\text { millions }\end{array}\end{array}$ & -2.137 & 3.31 & -0.65 \\
$\begin{array}{l}\text { Incoming interbank trading volume in EUR mil- } \\
\text { lions }\end{array}$ & 0.281 & 0.095 & -0.28 \\
$\begin{array}{l}\text { Outgoing interbank trading volume in EUR mil- } \\
\text { lions }\end{array}$ & 0.506 & 0.42 & 1.18 \\
$\begin{array}{l}\text { Financial customer trading volume in EUR mil- } \\
\text { lions }\end{array}$ & $* * * 0.411$ & 0.08 & 4.98 \\
$\begin{array}{l}\text { Commercial customer trading volume in EUR } \\
\text { millions }\end{array}$ & $* * 0.136$ & 0.07 & 2.06 \\
$\begin{array}{l}\text { Realized exchange rate volatility } \\
\text { Adjusted time-weighted open inventory position }\end{array}$ & 9.326 & 12.48 & 0.75 \\
\hline
\end{tabular}

Adjusted $\mathrm{R}^{2}$ 


\section{Table 7 Estimation of Lyons' (1995) baseline model for all incoming trades}

The dependent variable of the estimation equation below is $\Delta \mathrm{p}_{\mathrm{t}}$, the change in price between two successive trades measured in pips. $Q_{t}$ is order flow measured in EUR millions multiplied with a dummy variable for each counterparty group, i.e., other dealers or customers respectively. $I_{t}$ is the dealer's inventory at time $t$ multiplied with a dummy variable for each counterparty group. $\mathrm{D}_{\mathrm{t}}$ is an indicator variable picking up the direction of the trade, positive for purchases (at the ask) and negative for sales (at the bid) again multiplied with a dummy variable for each counterparty group. Estimation uses GMM and Newey-West correction. Standard errors in the third column, and $" * * * "$ and $" * * "$ indicate significance at the $1 \%$ and $5 \%$-level respectively.

$$
\begin{aligned}
\Delta \mathrm{p}_{\mathrm{t}}= & \alpha+\beta_{1} \mathrm{IBQ}_{\mathrm{t}}+\beta_{2} \mathrm{CUQ} \mathrm{t}_{\mathrm{t}}+\mathrm{IB}\left(\gamma_{1} \mathrm{I}_{\mathrm{t}}+\gamma_{2} \mathrm{I}_{\mathrm{t}-1}\right)+\mathrm{CU}\left(\gamma_{3} \mathrm{I}_{\mathrm{t}}+\gamma_{4} \mathrm{I}_{\mathrm{t}-1}\right)+\delta_{1} \mathrm{IBD}_{\mathrm{t}}+\delta_{2} \mathrm{IB}(-1) \mathrm{D}_{\mathrm{t}-1}+ \\
& \delta_{3} \mathrm{CUD}_{\mathrm{t}}+\delta_{4} \mathrm{CU}(-1) \mathrm{D}_{\mathrm{t}-1}+\eta_{\mathrm{t}}
\end{aligned}
$$

Panel A Results for all incoming trades

\begin{tabular}{lrrr}
\hline & Coefficient & Standard error & t-Statistic \\
\hline Constant & $* *-0.498$ & 0.23 & -2.21 \\
Order flow & & & \\
$\quad$ Interbank & -0.144 & 0.40 & -0.36 \\
$\quad$ Customer & 0.748 & 0.42 & 1.79 \\
Inventory & & & \\
$\quad$ Interbank trades & -0.253 & 0.35 & -0.73 \\
$\quad$ Lagged & 0.142 & 0.35 & 0.41 \\
$\quad$ Customer trades & $* * * 1.072$ & 0.41 & 2.64 \\
$\quad$ Lagged & $* * *-1.154$ & 0.41 & -2.84 \\
Direction & & & \\
$\quad$ Interbank trades, current & $* * * 2.783$ & 0.69 & 4.01 \\
$\quad$ Lagged & $* * *-1.524$ & 0.48 & -3.18 \\
$\quad$ Customer trades, current $\quad * * * 10.946$ & 0.47 & 23.06 \\
$\quad$ Lagged & $* * *-9.065$ & 0.44 & -20.38 \\
\hline Adjusted R ${ }^{2}$ & & & 0.23 \\
Durbin-Watson stat & & & 2.41 \\
Number of observations & & & 2,859 \\
\hline
\end{tabular}

\begin{tabular}{|c|c|c|c|}
\hline EUR & $\begin{array}{l}\text { Incoming, non- } \\
\text { speculative } \\
\text { interbank }\end{array}$ & Customers & Total \\
\hline Trading volume (millions) & 1,091 & 1,586 & 2,677 \\
\hline Estimated spread (basis points) & 1.524 & 9.065 & \\
\hline $\begin{array}{l}\text { Estimated revenue accounting for counterparty } \\
\text { groups only }\end{array}$ & 166,380 & $1,437,850$ & $1,604,230$ \\
\hline
\end{tabular}

Panel B Estimating revenues from customer business 


\section{Appendix Estimating the median bank size in foreign exchange trading}

The BIS data for the year 2001 states that worldwide turnover in foreign exchange on a gross basis is about USD 1,860 billions per year. Considering double counting this goes down to USD 1,200 billions. Of this, USD 387 billions is spot trading and about $35 \%$ of all spot trading is in USD/EUR. Assuming that all 2,530 participating banks trade in this leading currency pair, the mean daily USD/EUR spot trading per bank is then roughly USD 54 millions in net terms.

Due to the high concentration in this market, however, the median is much below the just discussed mean. A qualified estimation on the turnover of a median bank can be made for the German case. In Germany, the Deutsche Bundesbank approached 33 "reporting dealers" who are assumed to cover at least $95 \%$ of the foreign exchange market for the compilation of the BIS (2002) study. These dealers report a net spot trading of USD 26 billions, of which roughly $50 \%$ is in the USD/EUR market. Adding 50\% to achieve a gross figure, the mean turnover of a German bank in the market of interest is about USD 600 millions. However, the BIS shows that $75 \%$ of the volume is made up by the 5 largest banks. Their mean is then almost USD 3 billions per bank whereas the remaining 28 banks trade about USD 174 millions on average. Using additional information provided by the Deutsche Bundesbank on the distribution of turnover on these remaining banks, the relevant median figure for the 33 reporting banks is roughly USD 50 millions. The "true" median is even lower as the statistic does not cover the whole German foreign exchange market. Gehrig and Menkhoff (2004) mention 43 banks who conduct their own account foreign exchange trading in 2001 and there are many more banks in the market intermediating essentially customer orders. Thus, our bank is a fair representative of a median sized player in that market as the figure below illustrates. 


\section{Concentration in the German foreign exchange banking industry}

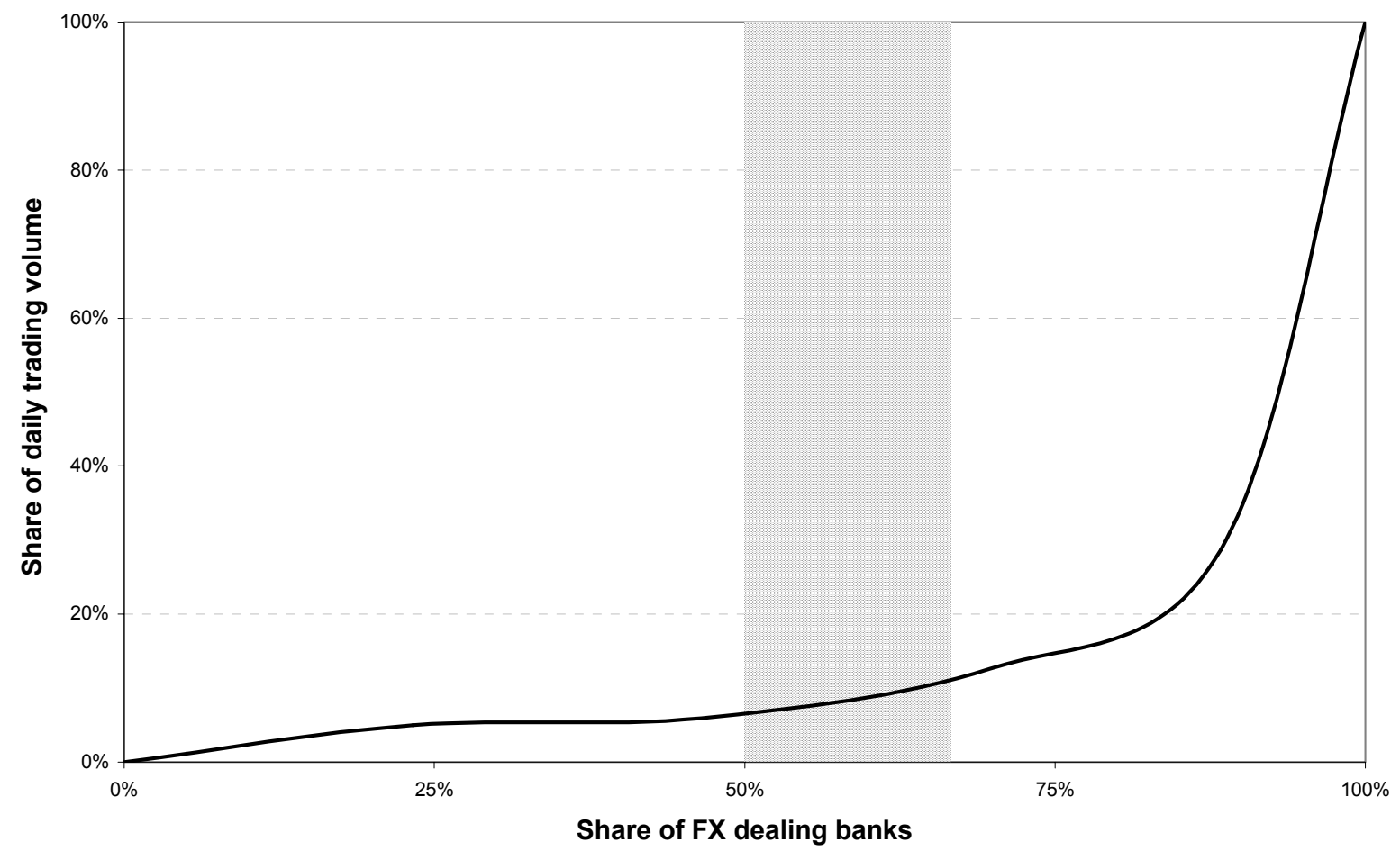

The diagram shows the concentration of the USD/EUR foreign exchange market in Germany for the year 2001. The horizontal axis shows the cumulated share of foreign exchange dealing banks, i.e., $100 \%$ represents 43 German banks engaged in foreign exchange own-account trading as well as customer service (33 "reporting" and 10 "non-reporting"). The vertical axis shows the cumulated share of the daily overall USD/EUR trading volume measured in USD. Thus, 75\% - 100\% represent the 11 largest banks (top 25\%) transacting more than $80 \%(20 \%$ $-100 \%$ ) of the daily USD/EUR turnover. The grey area marks the size category our bank falls into. Thus, our bank is a reasonable representative of a foreign exchange dealing bank in Germany in 2001. 